\title{
Water vapor formation causing reversible aerodynamic effect on the distribution of aero-algal forms
}

Pandkar J. T.

Department of Botany, Fergusson College, Pune- 4, India.

Received: 29-11-2017; Accepted: 13-12-2017

\begin{abstract}
Aerodynamic is a branch which deals with the study of takeoff and passive transport mechanism of bio-particles with the help of physical and mathematical modules. But there is not a single report on the aero-dynamic study with respect to manipulated meteorological condition. Nagpur being hottest during summer month, the frequency of using air coolers is very high. An air cooler is a device which evaporates water with the help of fan to bring down room temperatures which results into increase in room humi dity very much. To study the effect of humidity on the distribution and occurrence of aero algal forms sampling was carried out at three different sites, fitted with air cooler, from April- Mid May, using Rotarod sampler. Total 84 algal forms were recorded from 46 samples collected from three different sites. Cyanophyta was found to be dominant, followed by Bacillariophyta, Chlorophyta and Euglenophyta respectively. Trentipholia is found to be dominant algal forms followed by Chroococcos, Microcystis, Aphanocapsa, Chlorella \& Euglena respectively. Forms such as Chroococcidiopsis, Merismopedia, Aphanocapsa, Gleocapsa, Phormidium, Hormidium \& Pinnularia were recorded in equal proportion. Forms such as Chlorella, Microcystis, Phormidium \& Hormidium reported to be allergenic has been encountered. Irrespective of dry environmental condition with high temperature and low humidity (the condition considered to be favourable for dispersal of aero-algal forms, resulting into high concentration of air-borne algal flora) during sampling period, at all the three sites, minimum number of aero-algal forms were encountered due to increased humidity at the sampling sites. This can be due to manipulated micrometeorological conditions resulting into reversible aerodynamic effect on the aero-algal forms. Humidity of room air is increased by releasing water droplets in the atmosphere which act as a mode of reversible dispersion of aero-algal forms from higher level to the ground level, resulting into reduction in aero-algal counts at human breathing level. This finding, if experimented further with aero-algal and other bio-particles, can be good news for allergy patients.
\end{abstract}

Keywords: Manipulated micrometeorological conditions; Humidity; Aero-algal counts; Air- cooler; Aerodynamic; Allergy.

\section{Introduction}

Today's biggest concern all over the world is global warming due to presence of high level of aero-pollutants in the atmosphere. Bio-pollutants are one of its major constituent with algal forms as one of its important component. Number of Aerophycologist have contributed in this field regarding occurrence, distribution, variation in aeroalgal forms from various different places. But very few reports were their regarding aerodynamic of aeroalgal forms.

Aerodynamic is a branch which deals with the study of take - off and passive transport mechanism of bioparticles with the help of physical and mathematical modules. Patel et al., (2005), Karnik (1962), Shenoi et al., (1976) reported that some aquatic and terrestrial algae may become air-borne due to rain. Schlichting (1971, 1974), Woodcook (1948) suggested that bursting bubbles from breaking waves results into formation of aerosols (sea water nuclei) in oceanic air. Mc Craw (1967) during his studies of Taylor, Dry valley, Victoria land and Antarctica concluded that algae are frequently picked up from soil by strong wind currents. Broady (1979, 1984, 1996), Broady et al., (1991) recorded wind dispersal of terrestrial algae at Signy and Ross islands in Antarctica. Schlichting et al., (1978) suggested dispersal of algae by Antarctica flying birds. Wuthric et al., (1981) reported transport of diatoms by wind, waterbirds and aquatic insects in Europe. Similarly, correlation between meterological conditions with seasonal variation in aeroalgal counts has also been reported. Schlichting (1964), Brown et al., (1963), Ehresmann \& Hatch (1975), Carson \& Brown (1976), Roses et al., (1987,1989), Nair et al., (1983) and A.C. Devi \& N.I. Singh (2005), Sudershankumar et al., (1984) have discussed the

\section{*Corresponding Author:}

Dr. Jogita T. Pandkar,

Assistant Professor, Department of Botany,

Fergusson College, Pune- 4, India.

E-mail: jogita pandkar@yahoo.co.in relevance of air-borne algae with micrometerological and geographic parameters. Wharton et al., (1981, 1983) proposed an algal recycling table between fresh water, supra-glacial and terrestrial populations via an aerobiota which depends on the wind strength and direction. $\mathrm{R}$. Troma et al., (2001) suggested wind speed and direction having positive effect in dispersal of aero-algal forms. But there is not a single report on the aero-dynamic study with respect to manipulated meteorological condition. Hence the present work was considered for further studies.

\section{Material and Methods}

Nagpur being hottest during summer month, the frequency of using air coolers is very high. An air cooler is a device which evaporates water with the help of fan to bring down room temperatures which results into increase in room humidity very much. To study the effect of humidity on the distribution and occurrence of aero algal forms sampling was carried out at three different sites. All the sampling was carried out using Rotarod samples, (Perkins, 1957)

\section{Site- I}

Rotarod sampling from the bathroom of residential house at Pratap Nagar

Two samples (2nd May \& 22nd May) were collected from bathroom of residential house of Mr. Suresh Vinayak Khadke at Pratap Nagar. Sampler was placed on a 30" high stool, inside the bathroom. Sampling period is of 30 minutes/sample. 


\section{Site- II}

Rotarod sample of bed room fitted with an aircooler, at Pratap Nagar, Nagpur

Forty-three samples were collected from the bed room of Mr Suresh Vinayak Khadke. An air cooler has been fixed in one of the windows of this bed room and samples were collected during summer (from 1stApril- 13thMay) when this air cooler was being used every day. Sampling period is of 15 minutes/sample.

\section{Site- III}

Rotarod sampling from the air- cooler factory premises of 'Poly coolers', situated at Ravi Nagar, Nagpur

Single sample was collected on (16 $6^{\text {th }}$ April) from the premises of 'poly'coolers, Air cooler factory, situated at Ravi Nagar. Sampling period is of 30 minutes. During sampling at Site- I and Site- III, two strips of cellophane tape coated with petroleum jelly were mounted across the two bars of the rotarod sampler. After sampling one of the strip was mounted on a slide with glycerine jelly for direct microscopic examination and another strip was dropped in sterilized (6"x 1") test tube containing BG- 11 culture medium. Entire mounting and culturing procedures were carried out at the sampling site, to avoid contamination during transit. Cultures were allowed to grow under natural condition. Algal forms from cultures were isolated and mounted in glycerine, for further examination. At Site- II, only one strip of cellophane tape coated with petroleum jelly was mounted across the two bars of the rotarod sampler. After sampling the strip was mounted on a slide with glycerine jelly for direct microscopic examination. Identification of algal forms was done on the basis of morphological characters by comparing them with available literature. Fritsch (1935, 1945) and Desikachary (1959).

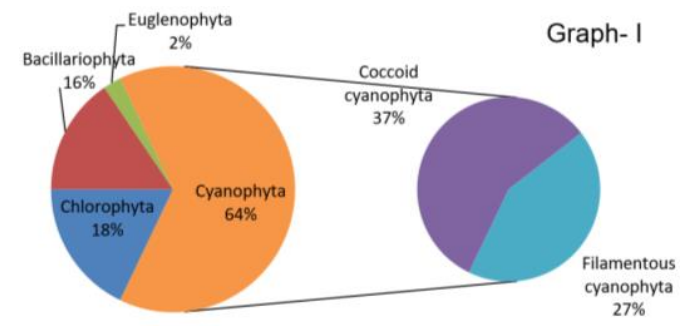

Class Frequency based on aeroalgal flora encountered from the samples

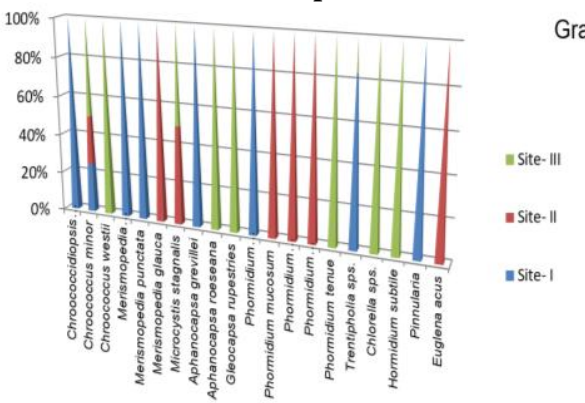

Comparative Account of Aeroalgal forms reported from sampling sites

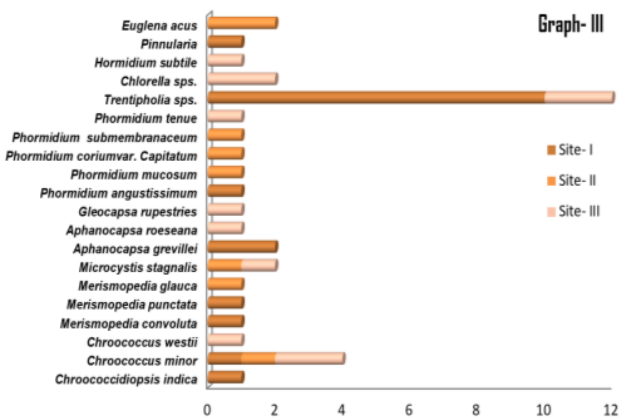

Frequency occurence of different aeroalgal forms during sampling period

\section{Results and Discussion}

Total 18 algal forms were recorded from two samples (2 Slides \& 2 Culture slides) obtained from Site- I sampling. All 18 forms were identified upto generic level \& 7 forms were identified upto species level. Chlorophyta was found to be dominant group represented by 10 algal forms followed by Cyanophyta 7 (6 Coccoid and 1 Filamentous) forms. Bacillariophyta was represented by a single form only. Two species of Merismopedia and one each species of Chroococcidiopsis, Chroococcus \& Phormidium were recorded (Observation Table- I)

Table I. Comparative account of aero-algal forms recorded at different sites

\begin{tabular}{clcccc}
\hline Sr.No. & \multicolumn{1}{c}{ Particulars } & Site- I & Site- II & Site-III & Total \\
\hline 1 & Number of samples & 4 & 43 & 1 & 46 \\
2 & Duration of sampling (Min.) & 60 & 654 & 30 & 735 \\
3 & Total algal forms & 18 & 54 & 12 & 84 \\
4 & Cyanophyta & 7 & 40 & 7 & 54 \\
5 & Coccoidcyanophyta & 6 & 19 & 6 & 31 \\
6 & Filamentous cyanophyta & 1 & 21 & 1 & 23 \\
7 & Chlorophyta & 10 & Nil & 5 & 15 \\
8 & Bacillariophyta & 1 & 12 & Nil & 13 \\
9 & Euglenophyta & Nil & 2 & Nil & 2 \\
10 & Chroococcidiopsis indica & 1 & Nil & Nil & 1 \\
11 & Chroococcus minor & 1 & 1 & 2 & 4 \\
12 & Chroococcus westii & Nil & Nil & 1 & 1 \\
13 & Merismopedia convoluta & 1 & Nil & Nil & 1 \\
14 & Merismopedia punctata & 1 & Nil & Nil & 1 \\
15 & Merismopedia glauca & Nil & 1 & Nil & 1 \\
16 & Microcystis stagnalis & Nil & 1 & 1 & 2 \\
17 & Aphanocapsa grevillei & 2 & Nil & Nil & 2 \\
18 & Aphanocapsa roeseana & Nil & Nil & 1 & 1 \\
19 & Gleocapsa rupestries & Nil & Nil & 1 & 1 \\
20 & Phormidium angustissimum & 1 & Nil & Nil & 1 \\
21 & Phormidium mucosum & Nil & 1 & Nil & 1 \\
22 & Phormidium coriumvar. Capitatum & Nil & 1 & Nil & 1 \\
23 & Phormidium submembranaceum & Nil & 1 & Nil & 1 \\
24 & Phormidium tenue & Nil & Nil & 1 & 1 \\
\hline
\end{tabular}




\begin{tabular}{clcccc}
\hline 25 & Trentipholia sps. & 10 & Nil & 2 & 12 \\
26 & Cblorella sps. & Nil & Nil & 2 & 2 \\
27 & Hormidium subtile & Nil & Nil & 1 & 1 \\
28 & Pinnularia sps & Nil & Nil & Nil & 1 \\
29 & Euglena acus & Nil & 2 \\
SITE- I & Sampling from the bathroom of residential house & & \\
SITE- II & Sampling from bed room, fitted with an air- cooler & \\
SITE- III & Sampling from the air- cooler factory premises of 'Poly coolers' \\
\hline
\end{tabular}

Out of 43 slides prepared from Site- II samples, 15 slides were recorded negative. Out of 28 positive slides, 54 algal forms were recorded. All 54 forms were identified upto class level, out of which 8 forms were identified upto generic as well as species level. Cyanophyta, the most frequent one, was represented by 40 (19 Coccoid and 21 filamentous) forms. Bacillariophyta was represented by 12 forms and 2 forms of Euglenophyta were recorded. Three species of Phormidium and one each species of Chroococcus, Merismopedia, Microcystis and Euglena were recorded (Observation Table- I). From the single sample collected from Site- III, 12 algal forms were recorded. All 12 forms were identified upto generic level out of which 8 forms were identified upto species level. Cyanophyta was represented by 7(6 Coccoid\& 1 Filamentous) forms followed by 5 Chlorophyta forms respectively. Two species of Chroococcus and one species each of Gleocapsa, Phormidium, Aphanocapsa, Microcystis and Hormidium could be identified (Observation Table- I). Chroococcidiopsis indica, Merismopedia convolute, Merismopedia punctate, Aphanocapsa grevillei, Phormidium angustissimum \& Pinnularia were recorded from Site- I only. Similarly, Merismopedia glauca, Phormidium mucosum, Phormidium corium var. capitatum, Phormidium submembranaceum \& Euglena acus were observed from site - II only (irrespective of the same sampling place with different spot). Forms such as Chroococcus westii, Aphanocapsa roeseana, Gleocapsa rupestries, Phormidium tenue, Hormidium subtitle \& Chlorella sps were reported from site III only. Microcystis stagnalis is reported from both site- II \& Site- III, were as Trentipholia sps is reported from both site- I \& site- III respectively. Chroococcus minor is the only aero-algal form recorded from all the three sites (GraphII).

Since sampling was conducted in month of April- May, the meteorological conditions were going to be constant for all the three sampling sites. But the results obtained at three different sites shows a huge diversity among the algal forms recorded (Graph- II). This clearly indicates that instead of only correlating metrological parameters during sampling period, emphasis should also be given for micro- metrological conditions prevailing at the sampling site during sampling.

Trentipholia is found to be dominant algal forms followed by Chroococcos, Microcystis, Aphanocapsa, Chlorella \& Euglena respectively. Forms such as Chroococcidiopsis, Merismopedia, Aphanocapsa, Gleocapsa, Phormidium, Hormidium \& Pinnularia were recorded in equal proportion (Graph- III).

Total 84 algal forms were recorded from 46 samples collected from three different sites. Cyanophyta was found to be dominant, followed by Bacillaciophyta, Chlorophyta and Euglenophyta respectively (Graph- I). N. K. Sharma et al., (2006) reported Cyanophyta as dominant group from Varanasi. All 84 forms were identified upto class level, 38 forms were identified upto generic level and 23 forms were identified upto species level. Cyanophycean forms recorded were Phormidium, Chrococcus, Aphanocapsa, Merismopedia, Microcystis, Gleocapsa \& Chroococcidiopus. Chlorophyceans forms recorded were
Trentipholia, Chlorella \& Hormidium. Bacillariophyta was represented by Pinnularia were as Euglenophyta was represented by Euglena (Observation table- I). Forms such as Chlorella, Microcystis, Phormidium \& Hormidium reported to be allergenic (Anostasia Chrisostomou et al., (2009), Bernstein and Safferman (1966, 1970), Paul Garham and Wayne Carmichael (1979), Mittal et al., (1973,1979), Goyal S. K (1976) \& Tilak (1992), has been encountered.

\section{Conclusion}

Sampling was carried out during dry summer month of April- May, with high temperature and relatively low humidity, was considered to be favourable condition for dispersal of various aero-algal forms as reported by $\mathrm{J}$. T. Pandkar (2008), Pandkar J. T. (2012), N.K. Sharma et al., (2006), R. Tromo et al., (2001) from Bedajoz (SW Spain) city reported maximum aero-algal concentration during May- June and shows positive correlation with temperature and negative correlation with humidity. But at all the three sites, minimum number of aero-algal forms were encountered, may be due to manipulated micrometeorological conditions resulting into reversible aerodynamic effect on the aero- algal forms (S.C. Santra (1987) reported limited Number of air-borne algae from June- Mid September due to high humidity and rain washing). Effect of Air-Cooler (which has become a common house hold item now a days) on aero-algal concentration was also studied for the first time. It was observed that an air- cooler, by increasing humidity of room air, reduces aero-algal counts. Humidity of room air is increased by releasing water droplets in the atmosphere which act as a mode of reversible dispersion of aero-algal forms from higher level to the ground level, resulting into reduction in aero-algal counts at human breathing level. This finding, if experimented further with aero-algal and other bio-particles, can be good news for allergy patients.

\section{Acknowledgement}

I would like to thank Dr. M. Z. Patel for his moral support during this work.

\section{References}

1. Anostasia Chrisostomou, Maria Moustake- goumi, StefenosSgardelis and Thomas Lamoras. Air- dispersed phytoplankton in Mediterranean River Reservoir system (Aliakmon- polyphytos, Grece). Journal of plankton research.; 31(8): 2009: 877-884, Print

2. Bernstein, I.L. and Safferman, R.S. Sensitivity of skin and bronchial mucosa to green algae. J Allergy. 28(3): 1966; 166173, Print

3. Bernstein, I.L. and Safferman, R.S. Viable algae in house dust. Nature. 227: 1970; 851-852, Print

4. Broady, P. A. Wind dispersal of terrestrial algae at Signy Island, South Orkney Island, Br. Antarct. Surv. Bull. 48: 1979; 99102, Print

5. Broady, P. A. Taxonomic and ecological investigations of algae on steam-warmed soil on Mt Erebus, Rooss Island, Antarctica. Phycologia. 23: 1984; 257-271, Print 
6. Broady, P. A. and smith. R. An initial report on an investigation of dispersal of algae in Southern Victoria land. BIOTAS Newsletter6: 1991; 5-7, Print

7. Broady P. A. diversity, distribution and dispersal of Antarctic terrestrial algae. Biodiversity Conservation. 5: 1996; 1207-1335, Print

8. Brown, R. M. Jr. Studies of Hawaiian fresh water and soil algae. I: the atmospheric dispersal of algae and fern spores across the Island of Oahu, Hawaii. In contributions to Phycology Ed. B. C. Parker and R. M. Brown, Jr. Allen Press, Lawrence, Kansas, U.S.A. 1963: 175-188, Print

9. Carson, J. L and Brown, R. M. Jr. The correlation of soil algae, airborne algae and fern spores with meteorological conditions on the island of Hawaii. Pacific Science. 30 (2): 1976; 197-205, Print

10. Devi A.C. and N.I. Sing .Relevance of Meteorological parameters on the occurrence of BGA in the air-borne dust in Imphal area.13th National Conf. Aerobiology, Inst. of Sci., Nagpur.2005: 6, Print

11. Ehresmann, D. W and Hatch, M. T. Effect of relative humidity on the survival of airborne unicellular algae. Appl. Microbial. 19: 1975; 352-357, Print

12. Goyal, S. K. Algae cause allergy. Science Reporter. 13: 1976; 364-366, Print

13. Jogita M. Patel and J. L. Tarar. Algal Air Spora of Nagpur through Rain water culturing. 13 $3^{\text {th }}$ National Conference on Aerobiology, Institute of Science Nagpur. 2005; abstract: D20, Print

14. JogitaT. Pandkar and J. L. Tarar. Vertical and Horizontal Aeroalgal Sampling at Nagpur. Recent Trends and Strategic Development in Biosciences. 2008; Abstract, Print

15. JogitaT. Pandkar. Effect of humidity on the occurrence of aero-algal forms. The Botanique. 17 (2): 2013; 112-115, Print

16. Karnik, C. R. A contribution to the rain water forms and aero sporaofJalgaon district. Science and Culture. 28: 1962; 475476, Print

17. Mc Craw J. D. Soils of Taylor Dry Valleys, Victoria Land, Antarctina, with notes on soils from other localities in Victoria Land. NZ. J. Geol. Geophys. 10; 1967; 498-539, Print

18. Mittal A, Agarwal M. K, Goyal S.K. and Shivpuri D. N. Preliminary studies on the allergenic algae of Delhi

19. Metropolitan area, Botanical aspectis. Asp of Aller and Appl. Immunol. 6: 1973; 41-50, Print

20. Mittal A, Agarwal M.K., and Shivpuri D.N. Respiratory allergy to algae clinical aspects. Ann of Allergy. 42: 1979; 253 - 256, Print

21. N. K. Sharma, AshwaniRai and Surendra Sing. Ecography, ISSN 0906-7590. 29 (5): 2006; 766-772, Print

22. N. K. Sharma, Surendra Sing and AshwaniRai. Diversity and seasonal variation of viable algal particles in the atmosphere of a sub-tropical city in India.Environmental Research. 102(13): 2006; 252-259, Print

23. Nair, P.K. K, Sundarshan Kumar and B. N. Pande. Occurrence of algae in the aerial biomass at Bareilly \& its bearing on human allergy. Curr. Sci.1983: 1199-1200, Print

24. Patil VS and Patil SR. Air Dispersion of Viable Algae in the extramural environment of Pune. International Journal of Advanced Research. 2(4) : 2014; 509-514, Print
25. Paul Gorham. R \& Carmichael, W.W. Phytotoxins from bluegreen algae. Pure \& Appl. Chem. 52: 1979; 165-174, Print

26. Perkins W.A (1957) Therotarod sampler. $2^{\text {nd }}$ semi-annual Rep. Aerosol. Lab. StandfordUni, CLH. 186: 1957; 1-66, Print

27. R. Troma, D. Recio, I. Silva and A. F. Munoz. A quantitative investigation of air-borne algae and lichen sporidia obtained from pollen traps in south-west spain. European Journal of Phycology. 36(4): 2001; 385-390, Print

28. Rosas. J, Roy-Ocotla. G, Mosino. P, Baez. A and Rivera. L Abundance and heterogeneity of algae in the Mexico City atmosphere. Geofis. Int. 26: 1987; 359- 373, Print

29. Rosas I, Roy-Ocatla G, and Carrera J. Meteorological effects on variation of airborne algae in Mexico, Int. J. Biomet. 33: 1989; 173-179, Print

30. Santra S.C. Airborne Algae of Calcutta Metropolis, Phykos.1987:71-74. , Print

31. Schilichting, H.E. Jr. Meteorological Conditions affecting the dispersal of airborne algae and protozoa. Lloydia. 27(1): 1964; 64-78, Prin

32. Schilichting, H. E. Jr. a. A preliminary study of algae and protozoa in sea foam. Bot. Marina. 14: 1971; 24-29, Print

33. Schilichting, H. E. Jr. b. Evaluation of biological requirements in a atmospheric monitoring system: Algae and protozoa in the atmosphere U.S, T B P Aerobiology Handbook No. 1 Univ. Michigan Ann. Arbor. 1971: 16-18, Print.

34. Schilichting, H. E. Jr. a. The survival of some fresh water algae under extreme environmental conditions. Trans. Amer. Microscop. Soc. 93: 1974; 610-613, Print

35. Schlichting, H. E. Jr, Speziale, B. J and Zink, R. M. Dispersal of algae and protozoa by Antarctic flying birds. Antarct. J. V. S. 13: 1978; 147-149, Print

36. Shenoi M. M and Ramlingam A. airspora of a sorghum field at Mysore. J. Palynology. XII (1\&2): 1976; 42-54, Print

37. Sudharshankumar, P.K.K. Nair and B.N. Pandey.Daily census of airborne algae at Bareilly.New Botanist. 11(2): 1984; 161168, Print

38. Tilak. S. T. Aerophycology. Ind. Jr. Aerobiol. spl.vol: 1992;1122, Print

39. Wharton R. A, Vinyard W.C, Parker B. C, Simmons G. M and Seaburg K. G. Algae in cryoconite holes on Canada glacier in southern victoria land, Antarctica. Phycologia. 20: 1981; 208211, Print

40. Wharton R. A and Vinyard W. C. Distribution of snow and ice algae in western north America, Madrono. 30: 1983; 201-209, Print

41. Woodcook, A. H. Note concerning human respiratory irritation associated with high concentration of plankton with mass mortality of marine organisms. Jr. Mar. res. 7: 1948; 5662, Print

42. Wuthrich, M. and Matthey, W. The diatoms of the "Tourbiere du Cachot" peat bog (Sziss Jura Mountains), III. Transport of diatoms by wind, waterbirds and aquatic insects. SchweizrischeZeitschrift fur Hydrobiologia. 42: 1981; 276-284, Print.

\section{Cite this article as:}

Pandkar J. T. Water vapor formation causing reversible aerodynamic effect on the distribution of aero-algal forms. Annals of Plant Sciences 7.1 (2018) pp. 1937-1940.

do http://dx.doi.org/10.21746/aps.2018.7.1.2 